\title{
Applications and implications of ecological energetics
}

3

4 Sean Tomlinson ${ }^{1,2 *}$, Sophie G. Arnall ${ }^{1}$, Adam Munn³ , S. Don Bradshaw ${ }^{1}$, Shane K. Maloney ${ }^{4}$,

$5 \quad$ Kingsley W. Dixon ${ }^{2,5} \&$ Raphael K. Didham ${ }^{1,6}$

6

$7{ }^{1}$ School of Animal Biology, University of Western Australia, Crawley 6009, Australia

$8 \quad$ 2Kings Park and Botanic Gardens, Fraser Avenue, West Perth 6005, Australia

$9{ }^{3}$ School of Biological Sciences, University of Wollongong, Wollongong 2522, Australia

$10{ }^{4}$ School of Anatomy, Physiology and Human Biology, University of Western Australia, Crawley

116009 , Australia

$12{ }^{5}$ School of Plant Biology, University of Western Australia, Crawley 6009, Australia

$13{ }^{6}$ CSIRO Ecosystem Sciences, Centre for Environment and Life Sciences, Underwood Ave,

14 Floreat WA 6014, Australia

15

16 * Corresponding author: Tomlinson, S. (Sean.Tomlinson@bgpa.wa.gov.au).

17

18

19 Abstract: 120 words

20 Text: 3685 words

21 Text Boxes: 3 (393, 400, 397 words)

22 Figures: 1

23 Tables: 1

24 References: 100 
The ecological processes that are crucial to an animal's growth, survival and reproductive fitness have energetic costs. The imperative for an animal to meet these costs within the energetic constraints of the environment drives many aspects of animal ecology and evolution, yet has largely been overlooked in traditional ecological paradigms. The field of 'ecological energetics' is bringing comparative physiology out of the lab and, for the first time, is becoming broadly accessible to field ecologists addressing real-world questions at many spatial and temporal scales. In an era of unprecedented global environmental challenges, ecological energetics opens up the tantalising prospect of a more predictive, mechanistic understanding of the drivers of threatened species decline, delivering process-based modelling approaches to natural resource management.

\section{Predicting species responses to rapid environmental change}

The 'Anthropocene' has become associated with rapid environmental change, not only in global land use and climate [1, 2], but in biodiversity, ecological stability and the ecosystem services on which humans depend [3]. The pace of change challenges our ability to understand shifting patterns of biotic interactions between species and their environment, and predict how these changes will influence conservation managers and environmental decision-makers into the future. Repeated calls have been made for more predictive, process-based approaches to modelling species' responses to global environmental challenges (e.g. $[4,5])$, yet limited progress has been made on this front in most areas of ecology or environmental impact assessment [6].

Arguably one of the most neglected factors in conservation management is a mechanistic understanding of the energetic requirements of an organism, and how those requirements influence population and community dynamics $[7,8]$. This is surprising, given 
the strong theoretical development of energetics as a fundamental determinant of ecological processes such as reproduction, dispersal, and interactions with other organisms [9]. For example, the M etabolic Theory of Ecology (M TE) has a long heritage of applying universal scaling laws for the relationship between metabolic rate, body size, and temperature (Box 1), to understand how energetics might govern ecological patterns [1014]. While M TE lends itself to interpretation of large scale macroecological or evolutionary patterns $[13,15]$, there are well-recognised limitations to what M TE can tell us about the variation in organismal responses to changing environmental conditions or management regimes [8]. In essence, universal scaling laws focus on conformity to a generalised relationship between metabolism and body size, rather than on inter- and intraspecific variability around the central tendency. One might reasonably argue that M TE predictions have little value in understanding why two similar-sized species, with similar metabolic rates, can respond quite differently to human disturbance or environmental change [9]. For ecologists and conservation biologists, then, there are important limitations on the relevance and application of metabolic scaling laws to 'real-world' questions at the spatial and temporal scales at which ecologists typically work. environments, and how to quantify these responses in free-living organisms at scales that are relevant to the interaction between the physiological traits of an organism and the environmental constraints on ecosystem energetics. Recent advances in monitoring the ecophysiological responses of free-living organisms might hold promise for greater predictive understanding of species distribution patterns across a wider range of scales. 
quantifying the physiological responses of species under idealised conditions, 'ecological energetics' aims to quantify the role of physiological processes in the ecological relations of animals (and plants) in their natural habitats [8]. Ecologists, of course, have been quick to point out that conditions are far from 'ideal' in the real world, and have been hesitant to adopt comparative physiological approaches. In ecological energetics, by contrast, the essential point is that any fundamental energetic traits determined by an organism's physiology are only ecologically relevant in the context of environmental constraints imposed on the availability or distribution of energetic resources [7-9, 16, 17]. For instance, the movement of animals throughout the landscape is largely driven by the interaction between a motivation to access resources (be they energetic, or reproductive), and the energy required to access those resources by making movements across or around physiologically-challenging environmental barriers [7]. To a great extent, then, the presence and local abundance of a species in a landscape might be driven by the suitability of the landscape for the animal's physiology.

In this article, we argue that the field of 'ecological energetics' is on the cusp of transforming the mechanistic study of ecological dynamics within the context of changing environmental conditions. We synthesize current understanding of the energetic basis to ecological processes (Figure 1) and explore how the widespread application of ecological energetics could provide a more mechanistic understanding of the complex interplay between physiological constraints and environmental limitations. We then describe recent advances in the technology required to cheaply and effectively test model predictions by measuring metabolic rate (amongst other traits) in a wide range of free-living animals. Finally, we provide empirical examples of the ways in which these principles can re-shape 
95

96

97

98

99

100

101

102

103

104

105

106

107

108

109

110

111

112

our understanding of conservation management in changing ecosystems. The study of energetic processes should no longer remain a specialised domain of physiology that ecologists avoid [8]. Instead, fields as diverse as ecology, conservation biology, natural resource management and landscape restoration will find important benefits in the application of ecological energetics.

\section{Ecological energetics: integrating physiological requirements within environmental} constraints

What we refer to as 'ecological energetics' represents the interpretation of ecophysiological data on organismal energy dynamics within the broader template of ecology and environmental management (Figure 1). Ecological energetics incorporates physiological responses to the environment extending beyond trying to understand fundamental energy requirements (such as thermal tolerance, thermoregulation and water turnover; red pathways in Figure 1), to recognise that many aspects of individual performance (the 'realised ecological distribution' in Figure 1) are constrained by the abiotic environment and/or by ecological interactions with other organisms (such as ecosystem productivity, competition, and associated costs of growth and reproduction; blue pathways in Figure 1). The domain of ecological energetics, therefore, is where the physiological requirements of organisms intersect the ecological constraints of the environment (the green regions of overlap in Figure 1).

Our synthesis of the principles underpinning ecological energetics (Figure 1) is founded on mechanistic, process-driven relationships between organisms and their environment [18]. We see this as fundamentally different from a purely correlative 
118 approach to measuring ecophysiological responses or species distribution modelling,

119 because it develops a niche envelope model incorporating the full range of physiological

120 tolerance limits, rather than those that are constrained by the ecosystems in which the

121 organism currently dwells. Of course, it is simply not practical to depict all of the potential

122 mechanistic pathways of energy flow in Figure 1, but the ultimate goal of ecological

123 energetics is to model these processes as precisely as possible, at spatio-temporal scales

124 that are relevant to a broad range of hypotheses. Process-based models have a greater

125 capacity than correlative models to predict beyond current ecological scenarios into novel

126 ecological space (and time), a key advantage when predicting the outcomes of rapid

127 environmental change, and articulating evidence-based management responses.

In ecological energetics, there is clear recognition that different environments impart different challenges for organisms with different physiological traits (Figure 1). By the same reasoning, it should be evident that management actions might need to prioritise different aspects of ecophysiological requirements or ecosystem energetic limitations to achieve diverse outcomes. For example, a successful single-species translocation program (Figure 1, bottom left) might prioritise the suitability of habitat that falls within the species' fundamental physiological tolerances (e.g.[19]), prior to quantifying potential ecosystem energetic limitations or theoretical carrying capacities (e.g. [20]). By contrast, multi-species ecosystem restoration (Figure 1, top left), might focus on identifying the diverse taxa that can provide key ecosystem services (e.g. [21]), prior to identifying the fundamental energetic requirements of the individual species. By quantifying the feedback loops detailed in Figure 1, it should be possible to inform the real-world responses of organisms and ecosystems to anthropogenic changes (both interventionist and unanticipated). Some of 
141 these responses can best be quantified using 'classical' ecological approaches, but many can

142 be measured accurately only by incorporating an ecological energetic perspective.

144 Generating process-based hypotheses

To be of practical value, conceptual models such as those depicted in Figure 1 must

146 be translated into practical hypothesis-testing tools that can deliver evidence-based

147 outcomes. For example, the energetic responses of individuals to variation in climate are

148 likely to be important drivers of population-abundance patterns [22], yet Clarke [23] argued

149 strongly that a clear framework linking physiology, climate, and macroecology is still lacking

150 (but see [5]). Correlative models, though useful, can provide misleading predictions under novel scenarios such as climate change [4, 5], and even some process-based models such as MTE can be uninformative if applied at inappropriate scales (Box 1). Fortunately, significant recent advances have also been made in the development of spatially-explicit niche envelope models that provide increasingly powerful tools to make the connections between physiological energetics, changing environmental conditions, and shifting patterns in the distribution and abundance of organisms [5].

In process-based models, climatic parameters are used to predict local microclimatic conditions, which can be integrated with known behavioural and thermal responses of the focal species to solve energy-, mass- and momentum-balance calculations [24]. This approach generates spatially-resolved predictions of microhabitats inhabitable by a focal species, producing an estimation of its 'thermodynamic niche' [25]. This mechanistic approach allows the prediction of distributional changes in response to novel environmental 
163 change scenarios. While any given process-based model might incorporate only a few of the

164 many ecological and evolutionary feedbacks inherent in Figure 1, there is real heuristic

165 advantage in placing these within a broader, more holistic conceptual context. Such an approach can be broadly applicable to a number of scenarios, including modelling habitat use, the movement [26] or activity patterns [27] of animals, the distributions of rare or range-restricted fauna (e.g. $[19,24,28]$ ), the energetics of migration $[29,30]$, the invasive spread of non-native organisms [5], and predicted effects of climate change on phenology [31], survival and reproduction [32]. Recent advances have seen mechanistic distributionmodels incorporated with energy budgets ([25, 33]; Box 1) to predict species' distributions on the basis of ecological requirements for persistence and reproduction.

174 of predicting 'habitable' ecological space, they effectively rule out vast sections of

175 hypothetical niche space as being metabolically inaccessible. For example, tolerance

176 thresholds and thermal response curves [34] can identify metabolically intolerable

177 ecological space where a species cannot survive or reproduce [5]. This in itself might provide useful management guidelines for proposed translocation sites [32], or identify geographic

179 space that represents a barrier to the natural dispersal of animals through a landscape, implicitly disrupting the ecological services that they provide (such as pollination or seed

181 dispersal). Quantifying the magnitude of these constraints informs the levels of management required to ameliorate human impacts. 
184 A new generation of techniques for testing ecological energetic hypotheses

185 It is important to point out that informative predictive models of species distribution and

186 abundance are not end-points in their own right, but are hypothetical starting points for

187 further empirical testing, particularly where they inform applied conservation outcomes. For

188 example, a model might predict climatically-suitable translocation sites for endangered

189 species [32], but local historical variation in land-use or productivity might impose energetic

190 constraints on the ability of a translocated population to survive and reproduce

191 (represented by the ecological feedbacks of Figure 1, sensu M cNab [35]). The modelling

192 itself could prove futile if not interpreted in its full ecological context, and this highlights the

193 importance of field measurements of metabolic rate (and other physiological parameters) in

194 varying environments. Only now are the techniques for making these kinds of

195 measurements becoming readily available to ecologists in the field.

For ecologists, it has traditionally been difficult to extrapolate laboratory-based

197 measures of energy requirements, as simple multiples of the Basal or Standard M etabolic

198 Rate (BM R or SM R respectively [36-38]), to dynamic ecological scenarios. What is required

199 are measures of field metabolic rate (FM R) in free-ranging animals [39] that reflect the cost

200 of existence for that animal in its natural environment. A wide array of techniques are now

201 available to measure the energetic requirements of nearly all animal taxa in almost any

202 environment, centred around two intrinsic scaling approaches: the scaling of isotope

203 measurements (Box 2) or biotelemetry data (Box 3) with FM R.

In isotopic approaches, the differential elimination of hydrogen and oxygen isotopes

(doubly-labelled water; DLW) has been used as a measure of the water turnover rate and 
207 ecophysiology. It is only in recent years that strong evidence has emerged to support other,

208 more cost-effective and equally accurate approaches to measuring FM R across the breadth

209 of taxa, environments and temporal scales at which ecologists work. For example, the

210 biological elimination of radio-isotopic rubidium has been shown to scale reliably with FM R

211 in a wide range of organisms including very small taxa dispersing over large spatial scales,

212 such as insects [40], which have not previously been within the scope of reliable FMR

213 measurements (Box 2).

214 In a complementary set of approaches, the miniaturisation of electronics over the last

215 decade has allowed cheap and effective measurement of heart rate or body movement

216 using telemetry to calculate FM R at unprecedented spatial and temporal scales (Box 3). The

217 fundamental assumptions of the approach are that activity requires energy at a predictable

218 rate that scales from cellular metabolism, and that energy use can be calculated from the

219 provision of oxygen to the tissues by blood-flow from the heart.

220 Each technique has its own assumptions, costs and benefits (Table 1), presenting a

221 wealth of affordable and accurate avenues for ecologists to measure the physiology of an

222 organism in its 'natural' state. Despite this, the measurement of FM R and its subsequent

223 interpretation within energy budgets has rarely been extended to any applied ecological

224 investigation or management outcome [19, 32, 41-44]. With these technical advances, the

225 way is now clear to measure and interpret the physiological constraints on organisms at

226 spatio-temporal scales that were previously unachievable for ecologists and conservation

227 managers. 
229 Real-world applications of ecological energetics in conservation management

In many respects, the 'adaptive management' paradigm of threatened species conservation $[45,46]$ masks a failure to understand the mechanistic basis of threatening

232 processes or management actions (see [45] for examples). With an increased capacity to

233 predict and measure the energetic responses of organisms to varying environmental

234 conditions [22, 47], comes the ability to translate empirical measurements into practical,

235 real-world outcomes. Here, we present a series of contrasting examples of the schema

236 conceptualised by Figure 1, published and hypothetical, that show how ecological energetics

237 can be used to develop a more predictive understanding of conservation management

238 actions. Current ecological and management applications are typically single-species

239 focused, but already show evidence of how cascading effects across species interaction

240 networks might be modelled more effectively in an ecological energetics framework.

At the species level, mechanistic modelling (contextualising the red pathways in

242 Figure 1) has shown how extreme climate-warming could impact reproductive processes (in

243 this case via altered incubation temperatures and juvenile thermal tolerance; Figure 1) in

244 the endangered tuatara (Sphenodon guntheri) in New Zealand, leading to functional

245 extinction by the mid-2080s [32]. The model also predicted thermally-suitable translocation

246 sites for insurance populations in the face of climate change [32], but these predictions

247 were not empirically tested by monitoring real translocated populations, nor by applying

248 expectations of FM R to known ecological productivity to estimate carrying capacity (the

249 blue pathways in Figure 1). This type of mechanistic quantification of the effects of climate

250 change to provide clear management targets [24] is rare, but is emerging as a more

251 detailed, robust and powerful management tool for species of conservation significance [19, 
25220 , 48]. However, there is still a requirement to incorporate empirical tests of predictions

253 under varying environmental contexts if any level of confidence is to be assigned to these

254 models.

In a contrasting example, the key threatening process for kittiwakes (Rissa tridactyla)

nesting in the Arctic Circle is human overfishing of food resources rather than climate warming, imposing a different set of energetic limitations on population persistence. The quantified energetic requirements of kittiwake foraging depend on time away from the nest [49] and local food availability [50], with an upper physiological limit on flight time and distance that the birds can cover [51]. Poor foraging success can reduce energetic reserves and consequently reduce reproductive output. Overfishing greatly exacerbates natural cycles of food availability, creating an ongoing reduction in foraging efficiency, with substantial population-level implications for kittiwakes. In this case, the focal species approach allows the estimation of cascading ecological feedbacks (blue pathways in Figure 1) between overfishing, reduced seabird foraging success, and energetic limitations, potentially leading to reduced reproductive output and population decline. However, most of these ecological feedbacks were not underpinned by mechanistic relationships per se, thus reducing the predictive power of the model. In addition, there will be a need to better consider variation in species' physiological tolerances (incorporating the red pathways in Figure 1) when testing whether management actions, such as increased fisheries exclusion zones around nesting habitats, might be particularly important in low productivity, rather than high productivity, years [52]. Nevertheless, this example does highlight how even a species-focused model can have community-wide relevance, because the driving mechanisms operate through a cascading series of effects of overfishing on marine foodwebs, and ultimately influence the foraging and reproductive capacity of seabirds. 
Detailed focal-species models have not yet been expanded to explicitly combine

277 quantitative energy budgets for multiple interacting species (Box 1). Notwithstanding, there

278 are no conceptual limits to applying ecological energetics to species interaction networks. In

279 practice, with current technology, there will be severe analytical constraints on the

280 modelling of energy budgets for even a modest number of interacting species. But even at

281 this level, explicit energetic modelling of simplified interaction networks could prove crucial

282 for predicting management outcomes. For example, Bergstrom et al. [53] describe the unforeseen ecological outcomes of manipulating the complex predator-prey relationships of

feral cats and rabbits in the fragile sub-Antarctic ecosystem of Macquarie Island. The

management scheme compromised seabird populations when the biological control of

rabbits caused cats to seek alternative prey, and subsequently compromised native vegetation when belated cat eradication released predation pressure on remaining rabbit populations. Mechanistic models describing the realised ecological distributions of both cats and rabbits (constructed from the red pathways and quantified using the blue pathways of Figure 1) could have been used to model hypothetical scenarios, such as the effect of singlespecies eradication (of either cats or rabbits) on the spatial dynamics of the other species. For example, reducing the rabbit population would increase density-dependent competition for food in cats, resulting in either prey-switching or predator population decline. The potential impact could be quantitatively predicted by scaling the energetic value of alternative prey items compared to rabbits to estimate the magnitude of predation rates on alternative prey species (such as native seabirds). Similarly, the inspection of ecosystem energetics and ecological feedback loops in Figure 1 would suggest that the effects of

298 subsequent cat eradication could be quantified by scaling the grazing rate of rabbits by the energetic value of foraging and the rate of increase of rabbit populations under reduced 
300

301

302

303

304

305

306

307

308

309

310

311

312

313

314

315

316

317

318

319

320

321

322

323

predation pressure. Although this is a hypothetical example, the potential advantages in linking energetic models for multiple interacting species of management concern certainly warrants empirical evaluation.

Exactly how far the community-wide, or even ecosystem-wide, application of ecological energetics can effectively be developed remains to be seen. Notwithstanding the many conceptual and methodological challenges yet to be overcome, we speculate that ecological energetics will come to play an important role in many aspects of ecosystem management. As an example, we consider how ecological energetics could play a crucial role in ecosystem management through the ambitious global target of restoring 150 million ha of degraded land by 2020 [54]. As pointed out by M enz and colleagues [54], successful ecological restoration extends beyond the replacement of vegetation cover, to the recovery of species interactions and ecological functioning $[54,55]$. The mechanistic, process-based approach underpinning ecological energetics could have great utility in the restitution of biologically-mediated interactions between plants and mutualists [21, 56], where ecosystem services (such as pollination or seed dispersal) might easily fail when the energetic requirements of key vectors are not met in the restored ecosystem. Speculatively, we might envisage a mechanistic model describing how changing land use patterns (such as clearing and subsequent restoration efforts in a mining landscape) might alter the thermo-energetics of key insect pollinators. The response of key taxa could not be accurately predicted using correlative approaches because they would be operating in a novel ecological space. They could, however, be predicted using niche envelope mapping and dynamic energy budgets, informing novel approaches to restoration programs (such as seed mixes that promote higher floral energy availability) to encourage the successful return of key pollination vectors. The successful return of pollinators presumably has down-stream impacts through 
324 better vegetative establishment, more rapid restoration success and increased biodiversity

325 leading to positive ecological and ecosystem energetic feedbacks (see Figure 1). These

326 hypothetical responses would have to be rigorously tested by measuring the

327 ecophysiological performance and population recruitment of key insect taxa under the

328 different management interventions hypothesised. However, we expect that understanding

329 and modelling the specific energetic requirements of key taxa will substantially increase the

330 cost-effectiveness of restoration and species translocation efforts.

332 Conclusion

333 The energetics of individual animals and the flow of energy through ecosystems

334 underlies many of the important processes that structure realised ecological niches,

335 community structure and ecosystem dynamics [7, 8]. Sagarin and colleagues [22] suggest

336 that the paucity of such information across the entire range of a species could be remedied

337 by the integration of new technologies and cross-disciplinary collaborative efforts. Although

338 techniques for quantifying energetics have existed for more than 50 years, advances in the

339 last few years now make the measurement of ecological energetics more accessible to field

340 ecologists than ever before, offering the opportunity to test hypotheses about the role of

341 energetics in ecology and evolution at a scale and level of detail that has previously been

342 impossible (e.g.[18, 33, 57]). Despite the importance of understanding ecological energetics,

343 recognition of the significance and accessibility of this information remains limited at the

344 applied level, and as such the ecological energetic component of most ecosystems or target

345 taxa remains a substantial knowledge gap in management programs [58]. We strongly

346 advocate the incorporation of ecological energetics into conservation management and

347 restoration plans at all scales and levels of application, from local to international. Given the 
simplicity and low cost of emerging technologies, a broader application of ecological energetics offers one avenue to bring a more mechanistic, process-based foundation to science, management, and policy in an era of rapid environmental change.

\section{Acknowledgements}

This work was funded by an Australian Research Council Linkage grant LP110200304. SGA was supported by an Australian Post-graduate Industry Award under ARC Linkage grant LP0990428. RKD was supported by an ARC Future Fellowship FT100100040. We thank David Watson and Nick Isaac for constructive comments that greatly improved the manuscript.

\section{References}

1. Ellis, E.C., et al. (2010) Anthropogenic transformation of the biomes, 1700 to 2000. Global Ecology and Biogeography 19, 589-606

2. Foley, J.A., et al. (2005) Global consequences of land use. Science 309, 570-574

3. Barnosky, A.D., et al. (2011) Has the Earth's sixth mass extinction already arrived? Nature 471, 51-57

4. Buckley, L.B., et al. (2010) Can mechanism inform species' distribution models? Ecology Letters 13, 1041-1054

5. Elith, J., et al. (2010) The art of modelling range-shifting species. M ethods in Ecology and Evolution 1, 330-342

6. Creagh, S. (2013) Government department commits to science-based policy. In The Conversation, https://theconversation.com/government-department-commits-to-science-basedpolicy-17056

7. McNab, B.K. (2002) The Physiological Ecology of Vertebrates; A View from Energetics. Cornell University Press

8. Bradshaw, S.D. (2003) Vertebrate Ecophysiology: An Introduction to its Principles and Applications. Cambridge University Press

9. Isaac, N.J.B., et al. (2012) Population and community ecology. In M etabolic Ecology: A Scaling Approach (Sibley, R.M., et al., eds), 77-85, Wiley-Blackwell

10. Irlich, U.M., et al. (2009) Insect rate-temperature relationships: Environmental variation and the Metabolic Theory of Ecology. American Naturalist 174, 819-835

11. O'Connor, M.P., et al. (2007) Reconsidering the mechanistic basis of the metabolic theory of ecology. Oikos 116, 1058-1072 
12. Terblanche, J.S., et al. (2007) Variation in scorpion metabolic rate and rate-temperature relationships: implications for the fundamental equation of the metabolic theory of ecology. Journal of Evolutionary Biology 20, 1602-1612

13. Algar, A.C., et al. (2007) A test of M etabolic Theory as the mechanism underlying broad-scale species-richness gradients. Global Ecology and Biogeography 16, 170-178

14. Kearney, M.R., and White, C.R. (2012) Testing metabolic theories. American Naturalist 180, 546-565

15. Fang, J., et al. (2012) Large-scale patterns of tree species richness and the metabolic theory of ecology. Global Ecology and Biogeography 21, 508-512

16. Andersen-Teixeira, K.J., and Vitousek, P.M . (2012) Ecosystems. In M etabolic Ecology: A Scaling Approach. (Sibley, R.M., et al., eds), 99-111, Wiley-Blackwell

17. Petchey, O.L., and Dunne, J.A. (2012) predator-prey relations and food webs. In M etabolic Ecology: A Scaling Approach. (Sibley, R.M., et al., eds), 86-98, Wiley-Blackwell

18. Kearney, M.R., et al. (2012) Balancing heat, water and nutrients under environmental change: a thermodynamic niche framework. Functional Ecology 27, 950-966

19. Mitchell, N., et al. (2013) Linking eco-energetics and eco-hydrology to select sites for the assisted colonization of Australia's rarest reptile. Biology 2, 1-25

20. Porter, W.P., et al. (2006) Po'ouli landscape bioinformatics models predict energetics, behavior, diets, and distribution on M aui. Integrative and Comparative Biology 46, 1143-1158 21. Menz, M.H.M., et al. (2011) Reconnecting plants and pollinators: challenges in the restoration of pollination mutualisms. Trends in Plant Science 16, 4-12

22. Sagarin, R.D., et al. (2006) M oving beyond assumptions to understand abundance distributions across the ranges of species. Trends in Ecology and Evolution 21, 524-530

23. Clarke, A. (2003) Costs and consequences of evolutionary temperature adaptation. Trends in Ecology and Evolution 18, 573-581

24. Kearney, M., and Porter, W.P. (2009) Mechanistic niche modelling: combining physiological and spatial data to predict species' ranges. Ecology Letters 12, 334-350

25. Kearney, M.R., et al. (2012) Balancing heat, water and nutrients under environmental change: a thermodynamic niche framework. Functional Ecology, doi: 10.1111/1365-2435.12020

26. Bartelt, P.E., et al. (2010) M odeling amphibian energetics, habitat suitability, and movements of western toads, Anaxyrus (=Bufo) boreas, across present and future landscapes. Ecological Modelling 221, 2675-2686

27. Levy, O., et al. (2012) Biophysical modeling of the temporal niche: From first principles to the evolution of activity patterns. American Naturalist 179, 794-804

28. Kearney, M., and Porter, W.P. (2004) Mapping the fundamental niche: physiology, climate and the distribution of a nocturnal lizard. Ecology 85, 3119-3131

29. Fort, J., et al. (2009) Thermodynamic modelling predicts energetic bottleneck for seabirds wintering in the northwest Atlantic. Journal of Experimental Biology 212, 2483-2490

30. Fort, J., et al. (2013) Energetic consequences of contrasting winter migratory strategies in a sympatric Arctic seabird duet. Journal of Avian Biology 44, 255-262

31. Kearney, M.R., et al. (2010) Early emergence in a butterfly causally linked to anthropogenic warming. Biology Letters 6, 674-677

32. Mitchell, N.J., et al. (2008) Predicting the fate of a living fossil: how will global warming affect sex determination and hatching phenology in tuatara? Proceedings of the Royal Society London B 275, 2185-2193

33. Kearney, M. (2012) M etabolic theory, life history and the distribution of a terrestrial ectotherm. Functional Ecology 26, 167-179

34. Angilletta, M.J. (2006) Estimating and comparing thermal performance curves. Journal of Thermal Biology 31, 541-545

35. McNab, B.K. (2006) The energetics of reproduction in endotherms and its implication for their conservation. Integrative and Comparative Biology 46, 1159-1168 
432 36. Elgar, M.A., and Harvey, P.H. (1987) Basal metabolic rates in mammals: allometry, phylogeny

433 and ecology. Functional Ecology 1, 25 - 36

434 37. Kleiber, M. (1932) Body size and animal metabolism. Hilgardia 6, 315-353

435 38. McNab, B.K. (1997) On the utility of uniformity in the definition of basal rate of metabolism.

436 Physiol Zool 70, 718-720

437 39. Ricklefs, R.E., et al. (1996) The relationship between basal metabolic rate and daily energy

438 expenditure in birds and mammals. American Naturalist 147, 1047 - 1071

439 40. Tomlinson, S., et al. (2014) Special K: testing the potassium link between radioactive

440 rubidium $\left({ }^{86} \mathrm{Rb}\right)$ turnover and metabolic rate. Journal of Experimental Biology, doi: 10.1242/

441 jeb.096222

442 41. Cooke, S.J., et al. (2012) Conservation physiology in practice: how physiological knowledge

443 has improved our ability to sustainably manage Pacific salmon during upriver migration.

444 Philosophical Transactions of the Royal Society of London B 367, 1757-1769

445 42. Metcalfe, J.D., et al. (2012) Conservation physiology for applied management of marine fish:

446 an overview with perspectives on the role and value of telemetry. Philosophical Transactions of the

447 Royal Society of London B 367, 1746-1756

448 43. Blaustein, A.R., et al. (2012) Ecophysiology meets conservation: understanding the role of

449 disease in amphibian population declines. Philosophical Transactions of the Royal Society of London

450 B 367, 1688-1707

451 44. Munn, A.J., et al. (2009) Field metabolic rate and water turnover of red kangaroos and sheep

452 in an arid rangeland: an empirically derived dry-sheep-equivalent for kangaroos. Australian Journal

453 of Zoology $57,23-28$

454 45. Armstrong, D.P., and Seddon, P.J. (2008) Directions in reintroduction biology. Trends in

455 Ecology and Evolution 23, 20-25

456 46. Seddon, P.J., et al. (2007) Developing the science of reintroduction biology. Conservation

457 Biology, 303-312

458 47. Blackburn, T.M ., and Gaston, K.J. (2003) Introduction: why macroecology? In Macroecology:

459 Concepts and Consequences. (Blackburn, T.M., and Gaston, K.J., eds), 1-14, Cambridge University

460 Press

461 48. Tracy, C.R., et al. (2006) The importance of physiological ecology in conservation biology. Integrative and Comparative Biology 46, 1191-1205 49. Fyhn, M., et al. (2001) Individual variation in field metabolic rate of Kittiwakes (Rissa tridactyla) during the chick-rearing period. Physiological and Biochemical Zoology 74, 343-355 50. Jodice, P.G.R., et al. (2003) Variation in energy expenditure among Black-legged Kittiwakes: Effects of activity-specific metabolic rates and activity budgets. Physiological and Biochemical Zoology 76, 375-388

51. Bevan, R.M., et al. (2002) The energetics of Gentoo Penguins, Pygoscelis papua, during the breeding season. Functional Ecology 16, 175-190

52. Caputi, N., et al. (2009) The effect of climate change on the western rock lobster (Panulirus cygnus) fishery of Western Australia. Canadian Journal of Fisheries and Aquatic Science 67, 85-96

53. Bergstrom, D.M., et al. (2009) Indirect effects of invasive species removal devastate World Heritage Island. Journal of Applied Ecology 46, 73-81

54. Menz, M.H.M., et al. (2013) Hurdles and opportunities for landscape-scale restoration. Science 339, 526-527

55. Tollefson, J. (2012) President prunes forest reforms. Nature 486, 13

56. Tylianakis, J.M ., et al. (2010) Conservation of species interaction networks. Biological Conservation 143, 2270-2279

57. Kearney, M.R., et al. (2010) Correlative and mechanistic models of species distribution provide congruent forecasts under climate change. Conservation Letters 3, 203-213

58. Boyer, A.G., and Jetz, W. (2012) Conservation biology. In M etabolic Ecology: A Scaling Approach. (Sibley, R.M., et al., eds), 271-279, Wiley-Blackwell 
59. Odum, H.T. (1983) Systems ecology : an introduction. Wiley

60. Munch, S., and Salinas, S. (2009) Latitudinal variation in lifespan within species is explained by the metabolic theory of ecology. Proceedings of the National Acadamy of Science 106, 1386013864

61. Isaac, N.J.B., and Carbone, C. (2010) Why are metabolic scaling exponents so controversial? Quantifying variance and testing hypotheses. Ecology Letters 13, 728-735

62. Chown, S.L., et al. (2007) Scaling of insect metabolic rate is inconsistent with the nutrient supply network model. Functional Ecology 21, 282-290

63. Angilletta, M.J.J. (2009) Thermal Adaptation: a Theoretical and Empirical Synthesis. Oxford University Press

64. Kooijman, S.A.L.M. (2000) Dynamic Energy and Mass Budgets in Biological Systems. Cambridge University Press

65. Kooijman, S.A.L.M . (2010) Dynamic Energy Budget Theory for M etabolic Organisation, 3rd Edition. Cambridge University Press

66. Lifson, N., and M cClintock, R. (1966) Theory of use of the turnover rates of body water for measuring energy and material balance. Journal of Theoretical Biology 12, 46-74

67. Nagy, K.A., and Costa, D.P. (1980) Water flux in animals: analysis of potential errors in the tritiated water method. American J ournal of Physiology Regulatory Integrative Comparative Physiology 238, R454-R465

68. Speakman, J.R. (1997) Doubly labelled water: theory and practice. Chapman \& Hall 69. Nagy, K.A. (1983) The doubly labeled water method: a guide to its use. University of California, Los Angeles Publication 12-1417, 1-45

70. Hillman, S.S., et al. (2009) Ecological and Environmental Physiology of Amphibians. Oxford University Press

71. Bevan, R.M., et al. (1995) Daily energy expenditure of tufted ducks: a comparison between indirect calorimetry, doubly labelled water and heart rate. Functional Ecology 9, 40-47

72. Bradshaw, S.D., and Bradshaw, F.J. (1999) Field energetics and the estimation of pollen and nectar intake in the marsupial honey possum, Tarsipes rostratus, in heathland habitats of SouthWestern Australia. Journal of Comparative Physiology B 169, 569-580

73. Bradshaw, S.D., and Bradshaw, F.J. (2007) Isotopic measurements of Field M etabolic Rate (FMR) in the Marsupial Honey possum (Tarsipes rostratus). Journal of M ammalogy 88, 401-407

74. Tomlinson, S., et al. (2013) From doubly labelled water to half-life; validating radio-isotopic rubidium turnover to measure metabolism in small vertebrates. Methods in Ecology and Evolution 4, 619-628

75. Odum, E.P., and Golley, F.B. (1963) Radioactive tracers as an aid to the measurement of energy flow at the population level in nature. In Radioecology (Schultz, V., and Kement, A.L., eds), 403-410, Reinhold

76. Wagner, C.K. (1970) Oxygen consumption, ambient temperature, and excretion of phosphorus-32 in cotton rats. Ecology 51, 311-317

77. Baker, C.E., and Dunaway, P.B. (1975) Elimination of ${ }^{137} \mathrm{Cs}$ and ${ }^{59} \mathrm{Fe}$ and its relationship to metabolic rates of wild small rodents. Journal of Experimental Zoology 192, 223-236

78. Peters, E.L. (1996) Estimating energy metabolism of goldfish (Carassius auratus) and southern toads (Bufo terrestris) from ${ }^{86} \mathrm{Rb}$ elimination rates. Copeia 1996, 791-804

79. Peters, E.L., et al. (1995) Estimation of the metabolic rate of the desert iguana (Dipsosaurus dorsalis) by a radionuclide technique. Physiological Zoology 68, 316-341

80. Cooke, S.J., et al. (2004) Biotelemetry: a mechanistic approach to ecology. Trends in Ecology and Evolution 19, 334-343

81. Green, J.A. (2011) The heart rate method for estimating metabolic rate: Review and recommendations. Comparative Biochemistry and Physiology A 158, 287-304

82. Steiger, S.S., et al. (2009) Low metabolism and inactive lifestyle of a tropical rain forest bird investigated via heart-rate telemetry. Physiological and Biochemical Zoology 82, 580-589 
534 83. Butler, P.J., et al. (2004) M easuring metabolic rate in the field: the pros and cons of the 535 doubly labelled water and heart rate methods. Functional Ecology 18, 168-183

536 84. Ropert-Coudert, Y., and Wilson, R.P. (2005) Trends and perspectives in animal-attached 537 remote sensing. Frontiers in Ecology and the Environment 3, 437-444

538 85. Wilson, R.P., et al. (2006) M oving towards acceleration for estimates of activity-specific metabolic rate in free-living animals: the case of the cormorant. Journal of Animal Ecology 75, 10811090

86. Green, J.A., et al. (2009) Estimating energy expenditure of animals using the accelerometry technique: activity, inactivity and comparison with the heart rate technique. Journal of Experimental Biology 212, 471-482

87. Bamford, O.S., and Maloiy, G.M . (1980) Energy metabolism and heart rate during treadmill exercise in the Marabou stork. Journal of Applied Physiology 49, 491-496

88. Bevan, R.M., et al. (1994) The use of heart rate to estimate oxygen consumption of freeranging Black-browed Albatrosses Diomedea melanophrys. Journal of Experimental Biology 193, 119137

89. Butler, P.J., et al. (1992) Relationship between heart rate and oxygen consumption during steady-state swimming in California Sea Lions. Journal of Experimental Biology 170, 35-42

90. Green, J.A., et al. (2000) Heart rate and rate of oxygen consumption of exercising macaroni penguins. Journal of Experimental Biology 204, 673-684

91. Hawkins, P.A.J., et al. (2000) Estimation of the rate of oxygen consumption of the Common Eider Duck (Somateria mollissima), with some measurements of heart rate during voluntary dives. Journal of Experimental Biology 203, 2819-2832

92. Leitner, P., and Nelson, J.E. (1967) Body temperature, oxygen consumption and heart rate in the Australian False Vampire Bat, Macroderma gigas. Comparative Biochemistry and Physiology 21, 65-74

93. McCarron, H.C.K., et al. (2001) Free-ranging heart rate, body temperature and energy metabolism in eastern grey kangaroos (Macropus giganteus), and red kangaroos (M acropus rufus) in the arid regions of south east Australia. Journal of comparative Physiology B 171, 401-411

94. McPhee, J.M., et al. (2003) Predicting metabolic rate from heart rate in juvenile Steller sea lions Eumetopias jubatus. Journal of Experimental Biology 206, 1941-1951

95. Owen, R.B.J. (1969) Heart rate, a measure of metabolism in Blue-winged Teal. Comparative Biochemistry and Physiology 30, 431-436

96. Nilssen, K.J., et al. (1984) Heart rate and energy expenditure in resting and running Svalbard and Norwegian reindeer. American Journal of Physiology Regulatory Integrated Comparative Physiology 246, R963-R967

97. Nolet, B.A., et al. (1992) Estimation of daily energy expenditure from heart rate and doubly labeled water in exercising geese. Physiological Zoology 65, 1188-1216

98. Williams, T.M., et al. (1993) The physiology of Bottlenose Dolphins (Tursiops truncatus): heart rate, meatbolic rate and plasma lactate concentration during exercise. Journal of Experimental Biology 179, 31-46

99. Spurr, G.B., et al. (1988) Energy expenditure from minute-by-minute heart-rate recording: comparison with indirect calorimetry. American Journal of Clinical Nutrition 48, 552-559

100. Ward, S., et al. (2002) Heart rate and the rate of oxygen consumption of flying and walking barnacle geese (Branta leucopsis) and bar-headed geese (Anser indicus). Journal of Experimental 
580 Table 1. Summary of recently-developed techniques for the measurement of field metabolic rate (FM R) in free-living organisms, with

581 limitations and applications to the study of ecological energetics in a range of target taxa. DLW $=$ doubly labelled water; ${ }^{86} \mathrm{Rb} \mathrm{kb}_{\mathrm{b}}=$ radioactive

582 rubidium turnover; HRT = heart rate telemetry; DA = dynamic accelerometry.

\begin{tabular}{|c|c|c|c|c|}
\hline Technique & Limitations on organism size & $\begin{array}{l}\text { Limitations on environmental } \\
\text { application }\end{array}$ & $\begin{array}{c}\text { Limitations on trophic } \\
\text { level }\end{array}$ & Model taxa \\
\hline
\end{tabular}

\section{Isotopic techniques}

DLW Medium to large.

Dry environments provide the most

Liquid diets are

Reptiles,

The high metabolic rate and metabolic

accurate DLW application because high

problematic, as are diets

birds,

water production of small animals often

water intake or water turnover relative

with high incidental water

mammals

means that complete isotope washout

to metabolic rate often result in

intake (such as in fish)

occurs very rapidly. Also, body fluid

overestimates of $\mathrm{CO}_{2}$ production.

because they often lead

subsampling is logistically challenging in

Fossorial environments result in re-

to high water turnover

small animals.

enrichment and underestimates of $\mathrm{CO}_{2}$ and overestimates of $\mathrm{CO}_{2}$

production.

production. 


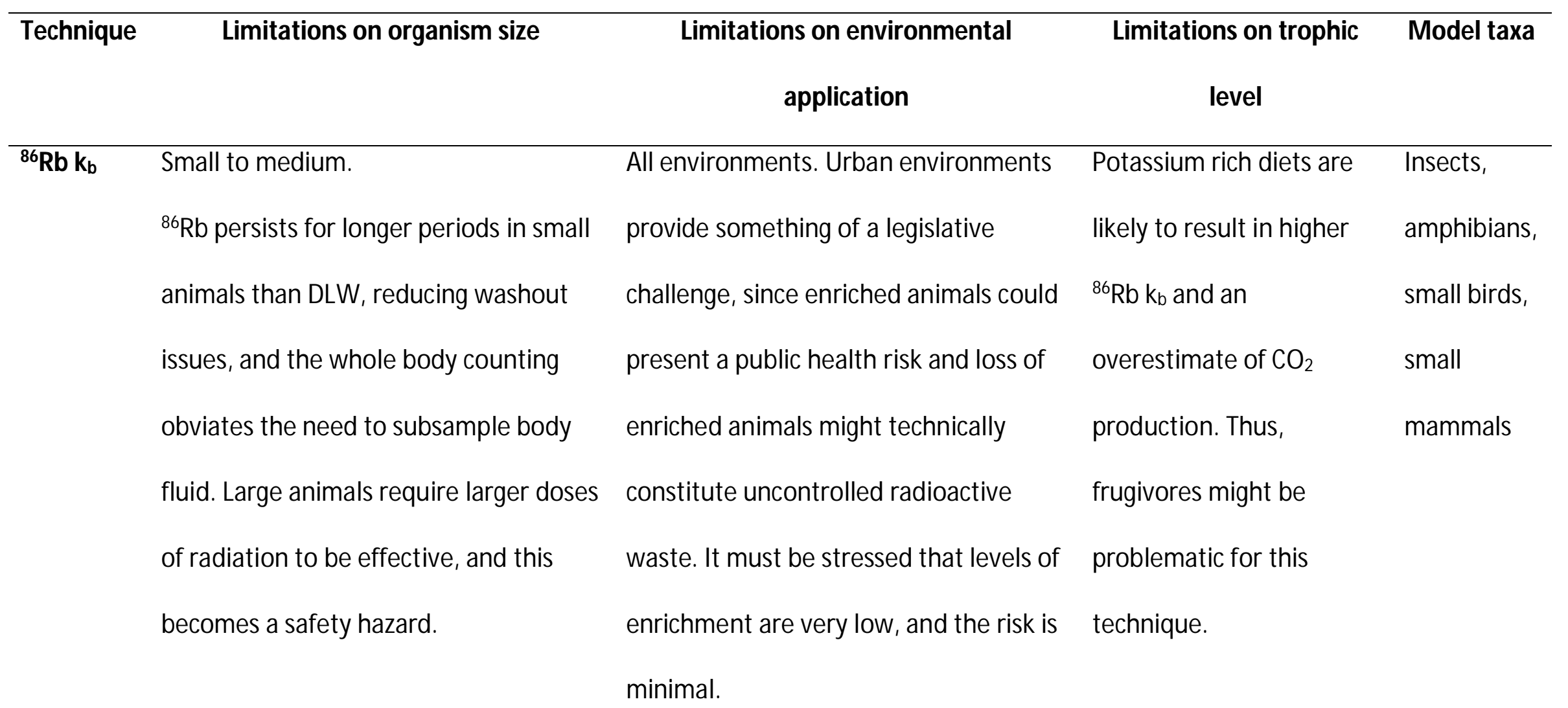

\section{Telemetry techniques}

HRT Medium to large.

Open and uncluttered environments

$N / A$

Birds,

where telemetry signals are less likely

mammals, 


\begin{tabular}{|c|c|c|c|c|}
\hline Technique & Limitations on organism size & $\begin{array}{l}\text { Limitations on environmental } \\
\text { application }\end{array}$ & $\begin{array}{l}\text { Limitations on trophic } \\
\text { level }\end{array}$ & Model taxa \\
\hline & $\begin{array}{l}\text { Body size is a factor of ethical } \\
\text { consideration when instrumenting an } \\
\text { animal. There is also a lower limit to } \\
\text { what is technically possible, and small } \\
\text { instruments are often associated with } \\
\text { very short battery life. }\end{array}$ & $\begin{array}{l}\text { to be scrambled by reflectance. M arine } \\
\text { environments. }\end{array}$ & & $\begin{array}{l}\text { especially } \\
\text { marine } \\
\text { birds and } \\
\text { mammals }\end{array}$ \\
\hline DA & $\begin{array}{l}\text { M edium to large. } \\
\text { The lower limit to what is technically } \\
\text { possible is smaller than HRT, but ethical } \\
\text { considerations and very short battery } \\
\text { life are important issues with small } \\
\text { instruments in small animals. }\end{array}$ & All environments. & $\mathrm{N} / \mathrm{A}$ & $\begin{array}{l}\text { Birds, } \\
\text { mammals, } \\
\text { especially } \\
\text { marine } \\
\text { birds and } \\
\text { mammals }\end{array}$ \\
\hline
\end{tabular}




\section{$584 \quad$ Figure caption}

585 Figure 1. Schematic illustration of the key pathways in the application of ecological

586 energetics to environmental management. For simplicity, not all potential pathways are

587 shown. Red pathways (bottom of diagram) represent animal energetic requirements,

588 established from mechanistic physiological data. Blue pathways (top of diagram) represent

589 landscape energetic limitations dictated by the biotic and abiotic environment. Green areas

590 indicate regions where ecological and physiological constraints interact to influence

591 ecological energetic requirements, and represent the domain of ecological energetic

592 studies. Black pathways indicate the ecological energetic feedbacks influencing ecosystem

593 stability. Differing management outcomes (such as ecosystem restoration, ecosystem

594 management, species recovery or translocation) will require a different rank ordering of

595 emphasis on different components of animal energetic requirements vs landscape energetic

596 limitations. See text for a detailed explanation.

597 


\section{ECOSYSTEM RESTORATION}

1. ecosystem feedbacks

2. fundamental tolerance

3. FMR

4. spatial energetics \& productivity

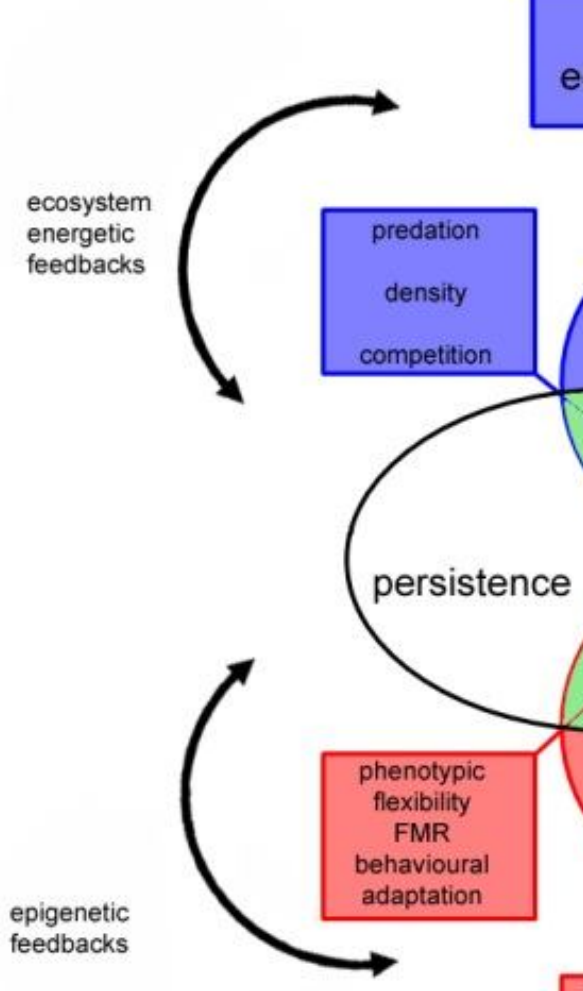

\section{TRANSLOCATION}

1. fundamental tolerance

2. spatial energetics \& productivity

3. FMR

4. ecological constraints

\section{ECOSYSTEM MANAGEMENT}

1. ecosystem feedbacks

2. fundamental tolerance

3. spatial energetics \& productivity spatial energetics

ecosystem productivity

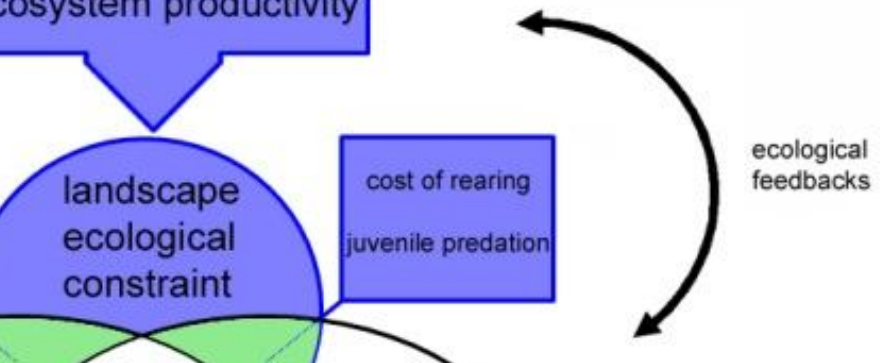

realised ecological distribution reproduction

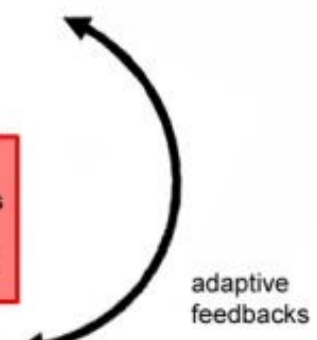

\section{thermal tolerance}

BMR \& WTR growth

\section{SPECIES RECOVERY}

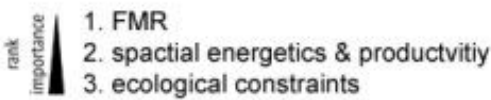




\section{Box 1. Energy as the currency of ecology}

602 The budgetary interpretation of ecosystem dynamics holds that energy is the central currency of ecology [59]. Ecological energetics aims to understand potential energetic constraints imposed on ecological patterns and processes by the metabolic requirements of interacting organisms. The metabolic basis to ecological energetics forms the foundation for a diverse set of mechanistic approaches to modelling species distributions, from expansive cross-species models such as the M etabolic Theory of Ecology (M TE), to intensive withinspecies models such as Dynamic Energy Budgets (DEBs) [10, 14].

MTE proposes that a universal scaling law defines the relationship between body size, metabolic rate and temperature, and can predict ecological patterns at the population[9], community- [9], or even ecosystem level $[13,15,16]$. The strength of this approach is that M TE can generate broad-scale macroecological predictions from a minimal number of parameters, which match some observed ecological patterns with remarkable accuracy [15, 60]. However, contentious debate surrounds the theoretical basis of M TE's power law exponent $[11,61]$, and the empirical fit to field data $[10,13]$. There is also the broader criticism that M TE inherently focuses on cross-species scaling trends, and brings little

617 mechanistic understanding to the (frequently large) degree of variation around the scaling relationship [10, 12,62], particularly in terms of metabolic and physiological responses to varying environmental conditions [63]. M oreover, M TE might be considered 'naïve' to the flexibility and complexity of the interplay between ecological and evolutionary processes

(Figure 1) that shape species responses and adaptation to changing environments. 
624 maintenance and structural growth equations for focal organisms [64, 65]. DEBs provide a

625 comprehensive underpinning to species-specific energetic constraints, which have recently

626 been incorporated into species distribution models [18, 33], predicting distribution on the

627 basis of ecological requirements for persistence and reproduction. A DEB delivers a flexible

628 model of energetics that can be applied in ecological space to estimate distribution and

629 abundance resulting from changing physiological or energetic demands of the landscape,

630 rather than relying on generalised macroecological scaling rules.

631 A future challenge is how to capitalise on the predictive power of DEBs at the spatial

632 and temporal scales that are most relevant to conservation management. Moreover, the

633 ability to predict the cascading community-wide effects of environmental change by

634 integrating DEBs for multiple interacting organisms remains unresolved. 
636 The application of comparative physiological methods to free-living organisms in their

637 natural environment has always been the 'holy grail' of ecophysiological studies. The

638 measurement of Field M etabolic Rate (FM R) and Water Turnover Rate (WTR) in free-ranging

639 animals began with the work of Lifson and M cClintock [66] and led to the development of

640 the doubly-labelled water (DLW) method to directly measure energy expenditure and water

641 flux in wild animals [67]. The rationale is that heavy isotopes of oxygen $\left({ }^{18} \mathrm{O}\right)$ are lost from an

642 organism as both $\mathrm{CO}_{2}$ and $\mathrm{H}_{2} \mathrm{O}$, whereas heavy isotopes of hydrogen $\left({ }^{2} \mathrm{H}\right.$ or $\left.{ }^{3} \mathrm{H}\right)$ are lost only

$643 \mathrm{as} \mathrm{H}_{2} \mathrm{O}[68,69]$. Therefore, the difference between the hydrogen and oxygen isotope

644 turnover rate is indicative of $\mathrm{CO}_{2}$ production $[68,69]$, which is linked to metabolic rate and energetic requirements. However, there are several assumptions behind the DLW technique that are not always met $[67,68]$ (see Table 1 ), thus restricting its use in some taxa, such as amphibians [70], diving birds or mammals [71], and organisms of small body size [72-74]. Finally, the ${ }^{18} \mathrm{O}$ isotope is expensive to procure and analyse $[68,69]$, and these costs have proven prohibitive for widespread general application in ecological studies [68].

Alternative techniques to measure FM R have long been sought to overcome the

constraints of DLW, including administering doses of various radioactive isotopes to determine whether radio-isotope elimination rate scales with metabolic rate [75]. Several isotopes have been investigated in this regard [76-79], and rubidium ( $\left.{ }^{86} \mathrm{Rb}\right)$ has been found to have the highest correlation with metabolic rate $[73,74,78,79]$. Practically, the isotope is introduced by ingestion or intraperitoneal injection $[73,74]$ similar to the stable isotopes used in the DLW technique. The subsequent rate of elimination (termed biological turnover; 
658 body size limitations and increases the temporal measurement period [73], as well as

659 providing the capacity to measure the FM R of very small animals, including invertebrates

660 [74], much more accurately than DLW. However, as yet there is still a paucity of validation

661 data comparing ${ }^{86} \mathrm{Rb}$ turnovers to $\mathrm{CO}_{2}$ production across a wide range of organisms $[73,74]$.

662 One of the challenges to be considered in the use of radioisotopes is the justifiable public

663 resistance to potential contamination. In general, the regulatory guidelines concerning

664 environmental and public health concerns can be easily adhered to without risk to data

665 integrity.

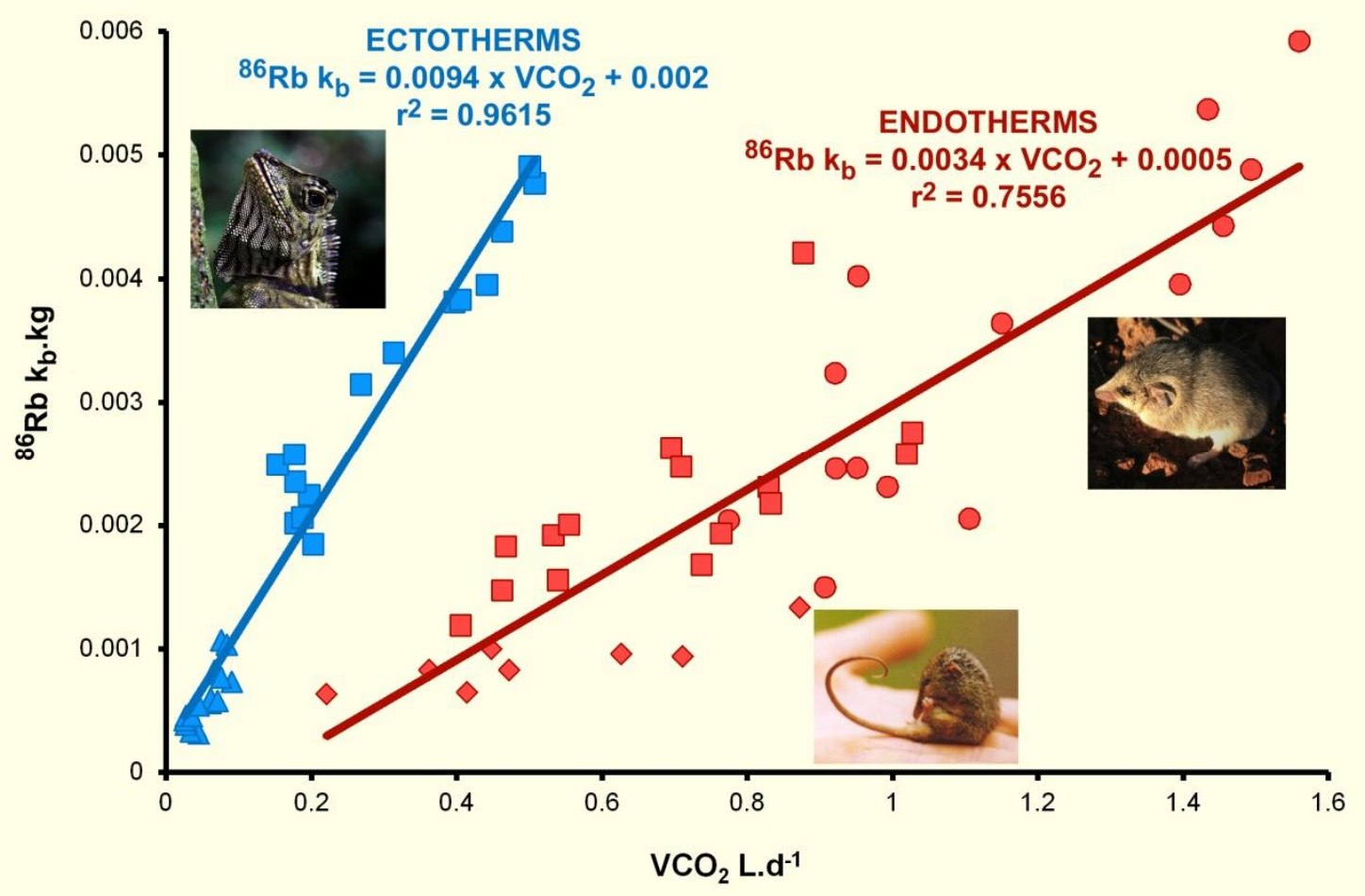

666

667 Box 2, Figure I. A meta-analysis of the relationship between rubidium isotope turnover and

$668 \mathrm{CO}_{2}$ production shows strong taxon-dependent scaling relationships [74]. All contributory

669 regressions were significant, and differences between endotherms and ectotherms are

670 speculated to relate to metabolic efficiency, unlike the expected isometry of DLW scaling

671 relationships. See Tomlinson et al. [74] for further details of symbols and species surveyed. 
673 The most widely used alternative approach to isotopic scaling of FM R is telemetry

674 techniques that exploit the correlation between heart rate and metabolic rate (see [80] and

675 [81] for review). Theoretically, an increase in cardiac output is required to furnish increased aerobic metabolism, including both physical activity and increased thermoregulatory

677 requirements [81]. Biotelemetry, such as Heart Rate Telemetry (HRT), involves instrumenting the animal with a radio-telemeter or data logger in close enough association to the heart or a major blood vessel to record individual heart beats. The HRT technique can be implemented in a minimally-invasive manner, especially if the instruments are fitted externally rather than implanted [82], reducing animal welfare concerns particularly in the case of species of conservation significance. Butler and colleagues [83] discuss extensively some other advantages of HRT, such as the ability to estimate the metabolic costs of specific activities, and "value-adding" when other physiological or behavioural variables such as body temperature, dive depth, acceleration and body position (attitude) are monitored concurrently and correlated with other features of the animal's behaviour and environment.

A meta-analysis of studies that have measured heart rate and metabolic rate suggests that metabolic rate scales predictably with heart rate (Box 3 Figure 1), but there remain reservations concerning the accuracy of biotelemetry, because heart rate is only one of a suite of physiological variables that drive changes in metabolic rate $[80,81]$. measures movement (acceleration). The rationale is that animal movement requires the use of energy, and that any movement should produce a corresponding, albeit dampened, 
694

movement of the animal's trunk (or body core $[84,85]$ ). The DA technique is in its infancy,

695 and reservations remain over its accuracy $[80,86]$.

696 Unlike isotope techniques, neither biotelemetry approach has any constraints on the

697 period during which the animal has to be recaptured, because data can be logged and

698 stored, and the 'signal' does not degrade or become washed out over time [83]. However,

699 where telemeters are sufficiently small to measure heart rate or movement in small

700 vertebrates, the battery life of small units is very short [80], leading to potential

701 compromises on data quality. While there are some definite advantages to pursuing

702 biotelemetry technology, these techniques remain at the very edge of our technical

703 advancement, and need to be carefully considered with the help of a skilled practitioner. 


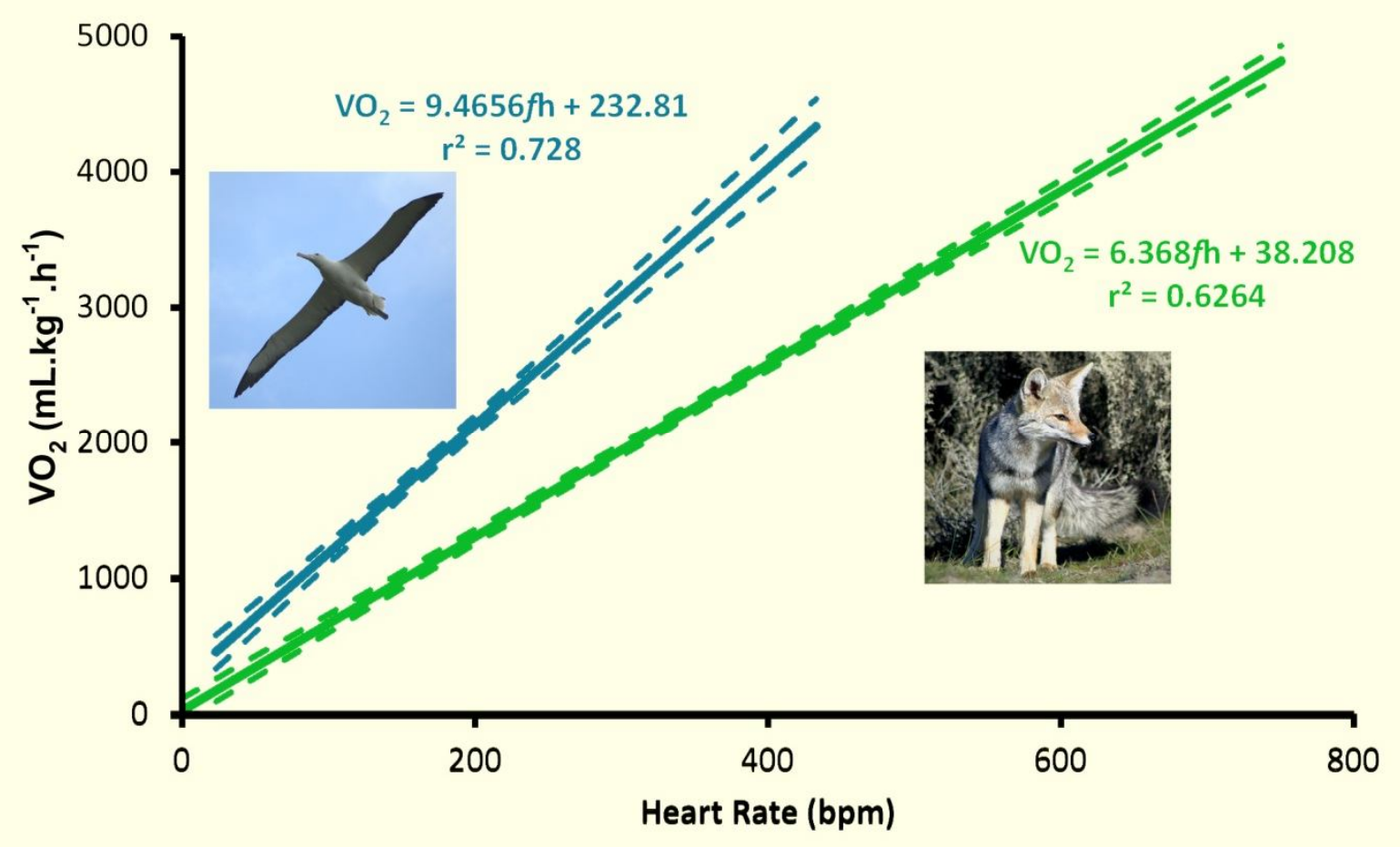

705

706 Box 3, Figure I. A meta-analysis of the relationship between heart rate and oxygen

707 consumption shows strong taxon-dependent scaling relationships in endotherms [82, 87-

708 100]. Both regressions are statistically significant, with dashed lines representing 95\%

709 confidence limits. Data points have been omitted for clarity. Body masses of the species

710 included range from 0.37 - $9.0 \mathrm{~kg}$ for birds, and 0.17 - $544.0 \mathrm{~kg}$ for mammals. 
711

712

713

714

715

716

717

718

719

720

721

722

723

724

725

726

727

728

729

730

731

\section{Glossary}

Basal metabolic rate (BM R): metabolic energy transformation in an organism in a rested, awake condition, fasted for sufficiently long to be in a post-absorptive state, and in a thermal environment that imparts no thermoregulatory requirement (the thermoneutral zone).

Biotelemetry: the application of an automated communications process to collect data remotely by monitoring various vital signs of an organism and logging or transmitting the resulting data to receiving equipment. Although any physiological data could theoretically be gathered, heart rate and movement patterns are often used to infer FMR.

Doubly-labelled Water (DLW): water in which both the hydrogen and the oxygen have been replaced with heavy isotopes, forming deuterium oxide-18 $\left(D_{2}{ }^{18} 0\right)$, differential turnovers of which can be used to calculate FM R.

Dynamic Energy Budget (DEB): theory that aims to identify simple quantitative rules for the organization of metabolism of individual organisms that can be understood from basic first principles. The theory integrates stoichiometric biochemical aspects of mass, energy, time, surface area and volume. The word "dynamic" refers to the life cycle perspective of the theory, where the budget changes dynamically over time.

Ecological Energetics: The integration of the physiological limits of an organism with the ecological constraints (biotic and abiotic) of the environment where it lives. These can be modelled mechanistically to generate hypothetical management guidelines, and 
can be tested empirically by measuring the physiology of free-ranging organisms within the environment.

Energetics: The branch of comparative physiology concerned with quantifying the metabolic cost of various aspects of an organisms' biological activity, including BM R or SM R, thermoregulation, digestion, growth, locomotion, reproduction, or any other set of activities.

Energy budget: the sum total of metabolic transformation costs available to an organism with which it might meet the requirements of normal biological activity.

Field metabolic rate (FM R): the energetic requirement of an organism pursuing normal biological activity, unrestrained in a natural environment, incorporating costs of locomotion, thermoregulation, digestion and behavioural activities.

Metabolic Theory of Ecology (M TE): an extension of Kleiber's Law which posits that the metabolic rate of organisms is the fundamental biological rate that governs most observed patterns in ecology. MTE is based on an interpretation of the relationships between body size, body temperature, and metabolic rate across all organisms.

Niche Envelope Mapping: process-driven (mechanistic) species distribution modelling aiming to link data on the limiting behavioural, morphological and physiological traits of organisms in relation to changing climate and ecology. This approach is distinct from correlative distributional modelling approaches, which inherently lack or have limited predictive capacity. 
752 Rubidium-86 turnover $\left({ }^{86} \mathrm{Rb} \mathrm{kb}_{\mathrm{b}}\right)$ : the biological elimination rate of radioactive rubidium, a biological analogue of potassium, which scales with metabolic rate and can be used to

755

756

757

758

759 infer FMR.

Standard metabolic rate (SM R): metabolic energy transformation in an organism under specified standard conditions (often those defining BM R), or imparting specific thermoregulatory requirements (i.e. thermal response curves)

\section{Outstanding Questions}

1. How can the influence of unpredictable shifts in spatial or temporal variability of energetic resources be modelled effectively?

2. How can species that are not in ecological or evolutionary stasis be effectively modelled with respect to changing patterns of distribution and abundance?

3. How well can epigenetic and memetic effects be incorporated into mechanistic models of distribution and abundance, and how can these effects be tested using ecological energetic approaches?

4. What are the inter-generational effects of changing ecological energetic constraints, and how can these effects be predicted under scenarios of ongoing, rapid and unpredictable change?

5. How do we manage ecological energetic factors crucial to human well-being where they might be in conflict with energetic factors crucial to biodiversity and ecosystem function? 